\title{
FITOMASSA E DECOMPOSIÇÃO DE RESÍDUOS DE PLANTAS DE COBERTURA PURAS E CONSORCIADAS ${ }^{(1)}$
}

\author{
Alexandre Doneda(2), Celso Aita(3), Sandro J osé Giacomini ${ }^{(4)}$, Ezequiel Cesar Carvalho \\ Miola $^{(2)}$, Diego Antonio Giacomini ${ }^{(5)}$,J anquieli Schirmann ${ }^{(5)} \&$ Rogério Gonzatto $^{(6)}$
}

\section{RESUMO}

O cultivo de plantas de cobertura, no outono/i nverno, na região do Planalto do Rio Grande Sul contribui para o sucesso do sistema plantio direto. No entanto, informações relativas à produção de fitomassa e decomposição de resíduos dessas espécies ainda são escassas para a região, sobretudo para espécies consorciadas. 0 experimento foi conduzido em Não-Me-Toque, RS, em um Latossolo Vermelho distrófico típico, avaliando-se nove tratamentos, sendo quatro constituídos por plantas de cobertura em culturas puras [centeio (Secale cereale L.), aveia-preta (Avena strigosa Schreb), ervilha forrageira (Pisum sativum subesp. arvense) enabo forrageiro (Raphanus sativus L. var. oleiferus Metzg)] e cinco por consórcios [(centeio + ervilha forrageira, centeio + nabo forragei ro, aveia + nabo forrageiro, centeio + ervilhaca (Vicia sativa L.) e aveia + ervilhaca)]. A dinâmica de decomposição dos resíduos culturais das plantas de cobertura foi avaliada em bolsas de decomposi ção, as quais foram distribuídas na superfície do solo e coletadas aos sete, 14, 21, 28, 57, 117 e 164 dias. 0 consórcio entre leguminosas e crucífera com gramíneas resultou em maior produção de fitomassa em relação ao cultivo destas em culturas puras. $\mathrm{O}$ nitrogênio ( $\mathrm{N}$ ) acumulado na parte aérea dos consórcios formados por ervilha forrageira e nabo com centeio e aveia foi semelhante ao da leguminosa e da crucífera em culturas puras e superou em $220,4 \%$ os valores de $\mathrm{N}$ observados para as gramíneas em culturas puras. Por meio do consórcio entre as espécies de cobertura foi possível reduzir a taxa de decomposição dos resíduos culturais, em comparação com as culturas puras da leguminosa e da crucífera.

Termos de indexação: mineralização, plantio direto, adubação verde, consorciação.

\footnotetext{
(1) Parte da Dissertação de Mestrado do primeiro autor apresentada ao Programa de Pós-Graduação em Ciência do Solo, Universidade Federal de Santa Maria - UFSM. Recebido para publicação em 17 de agosto de 2011 e aprovado em 02 de outubro de 2012.

(2) Doutorando, Programa de Pós-Graduação em Ciência do Solo, UFSM, Centro de Ciências Rurais, Departamento de Solos. Caixa Postal 221. Avenida Roraima, 1000, Camobi. CEP 97105-900 Santa Maria (RS). Bolsista do CNPq. E-mail: alexandredoneda@gmail.com; ezequielmiola@yahoo.com.br

(3) Professor Associado, Departamento de Solos, UFSM. Bolsista do CNPq. E-mail: celsoaita@gmail.com

(4) Professor Adjunto, Departamento de Solos, UFSM. E-mail: sjgiacomini@smail.ufsm.br

(5) Mestrando, Programa dePós-Graduação em Ciência doSolo, UFSM. E-mail: diegogiacomini14@hotmail.com; janquieli@hotmail.com

(6) Doutorando, Programa de Pós-Graduação em Ciência do Solo, UFSM. Bolsista CAPES. E-mail: rogonzatto@yahoo.com.br
} 


\title{
SUMMARY: BIOMASS AND DECOMPOSITION OF COVER CROP RESIDUES IN MONOCULTURE AND INTERCROPPING
}

\begin{abstract}
Theuse of cover crops in autumn/ winter, in thePlanalto region of Rio Grandedo Sul, contributes to the success of the no-tillagesystem. However, information about the bi omass production and decomposition of such species in theregi on is still scarce, especially for cover crop species in consortium. Theexperiment was conducted in Não-MeToque, RS, on an Oxisol, evaluating ninetreatments of four cover crops in monoculture [rye (Secale cereale L.), oat (Avena strigosa Schreb), pea (Pisum sativum subsp. arvense), and wild radish (Raphanus sativus L. var. oleiferus Metzg)] and fivein intercropping [(rye + pea, radish + rye, oat + radish, rye + vetch (Vicia sativa L.) and oat + vetch)]. The decomposition dynamics of cover crop resi dues was evaluated in litter bags which weredistributed on thesoil surfaceand coll lected after seven, 14, 21, 28, 57, 117, and 164 days. Leguminous and cruciferous intercropped with Gramineae species resulted in greater biomass production compared to cultivation in monocul ture Thenitrogen ( $\mathrm{N}$ ) accumul ated in the pea and wild radish pl ants intercropped with ryeand oat was similar to the $\mathrm{N}$ in theleguminous and cruciferous monocul tures and exceeded the N values observed for the Gramineae species in monoculture by $220.4 \%$. By intercropping cover crops it was possible to reduce the decomposition rate of crop residues compared to themonoculture of leguminous and cruciferous species.
\end{abstract}

Index terms: mineralization, no-tillage, green manure, cover crops in intercropping.

\section{INTRODUÇÃO}

A utilização de plantas de cobertura de sol o vem ganhando cada vez mais espaço em sistema plantio direto (SPD) nas áreas agrícolas do Sul do Brasil. Por meio dessa prática, busca-se atender a uma das premissas básicas do SPD, que é a adequação de sistemas de rotação esucessão de culturas de modo a otimizar o aporte de material orgânico e nutrientes, bem como proteger osolo dos processos erosivos (Silva et al., 2007; Marcelo et al., 2009). Para isso, é fundamental selecionar plantas de cobertura com maior potencial em produzir fitomassa e acumular, principalmente, carbono $(\mathrm{C})$ e nitrogênio $(\mathrm{N})$ ), além de conhecer a dinâmica de decomposi ção e liberação de nutrientes dos resíduos culturais.

O uso de leguminosas como plantas de cobertura constitui uma importante fonte de $\mathrm{N}$ ao sol o, pelo fato de se associarem simbioticamente com bactérias capazes de transformar o $\mathrm{N}_{2}$ atmosférico em $\mathrm{NH}_{3}$ no processo de fixação biológica de N (FBN) (Silva et al., 2006; Aita \& Giacomini, 2006). Apesar dessa característica das leguminosas, o que representa uma vantagem, oseu uso noSul do Brasil ainda érestrito, relativamente às gramíneas, com destaque para a aveia. I sso ocorre pelo seu maior custo de implantação, menor rendimento de matéria seca, desenvolvimento inicial mais lento e rápida decomposição dos resíduos culturais, além da possi bilidadedeserem hospedeiras de pragas (Silva et al., 2006).

Contudo, para a regiãoSul do Brasil, a utilização de leguminosas em culturas puras como plantas de cobertura de solo antecedendo o milho tem demonstrado que a decomposição dos resíduos culturais ocorre rapidamente, com o solo ficando desprotegido logo no início do cultivo, além de não haver boa sincronia entrea liberação ea demanda de N pelo milho (Aita $\&$ Giacomini, 2003; Silva et al., 2006). Por outrolado, quando são utilizadas gramíneas em culturas puras como plantas de cobertura no outono/inverno, elas podem causar prejuízos às culturas em sucessão, em razão da provável imobilização mi crobiana de $\mathrm{N}$ do solo durante a sua decomposi ção, embora elas possuam alta capacidade de extração de $\mathrm{N}$ do solo (Silva et al., 2006 ; Kramberger et al., 2009). Apesar disso, a aveia éa principal planta decobertura de inverno utilizada no Sul do Brasil, em virtude do el evado rendimento de matéria seca, da facilidadena produção, da aquisição de sementes e implantação, além da rapidez na formação de cobertura (Silva et al., 2006). A busca de alternativas à aveia, com vistas a produzir uma cobertura morta eficiente na proteção do solo e, ao mesmo tempo, no fornecimento de $\mathrm{N}$ à cultura em sucessão, constitui um desafioà pesquisa local .

Assim, o consórcio entre espécies de plantas de cobertura desolo- principalmente entre gramínease leguminosas ou crucíferas - pode ser uma estratégia eficientepara minimizar esses problemas observados com as culturas puras. I sso porquea relação $\mathrm{C} / \mathrm{N}$ dos resíduos culturais dos consórcios entre espécies é intermediária àquela encontrada notecido vegetal das espécies cultivadas isoladamente e a relação C/N é considerada uma das principais características controladoras da velocidadededecomposiçãoeliberação de N dos resíduos culturais (Giacomini, 2001).

Estudos relativos ao consórcio de plantas de cobertura ainda são escassos no Brasil, sendo restritos quase que exclusivamente ao consórcio entre aveiapreta e ervilhaca comum (Basso, 1999; Heinrichs et al., 2001). É necessário, portanto, buscar novas espécies para o cultivo consorciado, procurando 
estabel ecer a proporção adequada de cada espécie no consórcio, de modo a maximizar a produção de fitomassa eadição de C enutrientes aosolo (Giacomini et al., 2003).

Não obstante, a decomposição e liberação de nutrientes dos resíduos culturais de plantas de cobertura do solo é, também, um aspecto ainda relativamente pouco estudado (K liemann et al., 2006; Torres et al., 2008), o que evidencia a necessidade de intensificar os trabalhos nessa área, sobretudo sob condiç̧̃es de plantio direto.

O objetivo destetrabalho foi avaliar a produção de fitomassa e a decomposição de resíduos culturais de plantas de cobertura no outono/inverno, em culturas puras e consorciadas, antecedendoa cultura do milho, em sistema plantio direto na região do Planalto do RioGrandedoSul.

\section{MATERIAL E MÉTODOS}

O trabalhofoi conduzido em campono anoagrícola de 2008/2009, na localidade de Mantiqueira, no município de Não-Me-Toque, RS, local izada a 28० 29' delatitude sul, longitude de $52^{\circ} 51^{\prime} \mathrm{W}$ GrW ealtitude de $493 \mathrm{~m}$. O clima da região ésubtropical úmido, tipo Cfa, conforme classificação de Köppen. O solo do local édassificado como LatossoloVermel ho distróficotípico (E mbrapa, 2006), pertencente à Unidade de Mapeamento Passo Fundo (Brasil, 1973). As características do solo são mostradas no quadro 1. Anteriormente à implantação do experimento, a área foi cultivada, durante dois anos, com a sucessãotrigo/ soja em SPD.

As plantas de cobertura foram semeadas em 17/ 05/2008, em SPD, sobre resíduos culturais de soja. O

Quadro 1. Características física e quími cas do solo do experimento nas camadas amostradas

\begin{tabular}{|c|c|c|}
\hline \multirow{2}{*}{ Característica } & \multicolumn{2}{|c|}{ Camada } \\
\hline & $0-5$ & $5-15$ \\
\hline & & 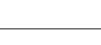 \\
\hline Argila $\left(\mathrm{g} \mathrm{kg}^{-1}\right)$ & 460,0 & 560,0 \\
\hline $\mathrm{pH}\left(\mathrm{H}_{2} \mathrm{O}\right)$ & 5,6 & 5,3 \\
\hline Índice SMP & 6,4 & 6,2 \\
\hline$P\left(\mathrm{mg} \mathrm{L}^{-1}\right)$ & 22,8 & 20,8 \\
\hline $\mathrm{K}\left(\mathrm{mg} \mathrm{L}^{-1}\right)$ & 424,0 & 260,0 \\
\hline $\mathrm{Al}^{3+}\left(\mathrm{cmol}_{\mathrm{C}} \mathrm{L}^{-1}\right)$ & 0,0 & 0,5 \\
\hline $\mathrm{Ca}^{2+}\left(\mathrm{cmol}_{\mathrm{c}} \mathrm{L}^{-1}\right)$ & 5,9 & 4,2 \\
\hline $\mathrm{Mg}^{2+}\left(\mathrm{cmol}_{\mathrm{C}} \mathrm{L}^{-1}\right)$ & 2,5 & 1,8 \\
\hline $\mathrm{H}+\mathrm{Al}\left(\mathrm{cmol}_{\mathrm{C}} \mathrm{L}^{-1}\right)$ & 2,8 & 3,5 \\
\hline CTC efetiva $\left(\mathrm{cmol}_{C} \mathrm{~L}^{-1}\right)$ & 9,5 & 7,2 \\
\hline Saturação por bases (T, \%) & 77,0 & 65,0 \\
\hline Matéria orgânica (\%) & 3,5 & 2,2 \\
\hline
\end{tabular}

delineamento experimental foi de blocos ao acaso com quatro repetições, em parcelas de $200 \mathrm{~m}^{2}$ (20 x 10 m). Os tratamentos consistiram do cultivo de plantas de cobertura de inverno, em cultura pura ou em consórcio: centei o (SecalecerealeL.) (C); aveia-preta (Avena strigosa Schreb) (A); ervilha forrageira (Pisum sativum subesp. arvense) (EF); nabo forrageiro (Raphanus sativus L. var. ol eiferus Metzg) (NF); centeio + ervilha forrageira $(C+E F)$; centeio + nabo forrageiro(C +NF); centeio +ervilhaca comum (Vicia sativa $L$.) $(C+E C)$; aveia + naboforrageiro $(A+N F)$; aveia +ervilhaca comum (A +EC); e pousio (vegetação espontânea).

A quantidade de sementes utilizada nas espécies em cultura pura, em kg ha-1, foi de 70 no centeio, 80 na aveia, 70 na ervilha e 20 no nabo. Para os tratamentos com consórcio, utilizou-se metade da quantidade de sementes empregada em cada espécie em cultura pura. N os consórcios contendo ervilhaca, a quantidadedesementes dessa espéciefoi de $40 \mathrm{~kg} \mathrm{ha}^{-1}$. A semeadura detodas as espécies foi mecanizada, com semeadora para plantio dir eto (PD) e sem adição de fertilizantes, utilizando-se o espaçamento de $17 \mathrm{~cm}$ entrelinhas. Em sucessão às plantas de cobertura foi semeado milho, em PD, no dia seguinte ao manejo das espécies.

Aos 120 dias da semeadura foi feita a coleta das plantas, quando o nabo ea ervil ha estavam noestádio de florescimento pleno; o centeio, no início do florescimento; a aveia, no emborrachamento; e a ervilhaca, ainda sem a presença de flores. Foram coletadas duas subamostras de $0,49 \mathrm{~m}^{2}$ por parcela, sendo uma para a determinação da produção de matéria seca (MS), concentração de C orgânico edeN total eoutra para determinação da matéria seca aoar (MSA), visando avaliar a decomposi ção dos resíduos culturais. Nos consórcios, procedeu-seà separação das espécies, a fim de determinar a contribuição individual decada uma delas. Na subamostra para determi nação da MS e acúmulo de $\mathrm{C}$ e N, o material coletado foi seco em estufa a $65^{\circ} \mathrm{C}$ até peso constante, pesado, moído em triturador de forragens, subamostrado e moído novamenteem moinho Willey. Os teores de N total eC orgânico foram determinados por combustão seca em um Autoanal isador Elementar modelo F lash EA 1112.

Na subamostra coletada para avaliar a decomposição, o material coletado foi submetido à secagem ao ar, até massa constante, para determinação da MSA e, a partir dela, estabelecer a quantidade de resíduo a ser adicionada nas bolsas utilizadas para aval iar a decomposição. As plantas de nabo foram separadas em talo, fol ha e inflorescência. Quantoàs demais espécies avaliadas, nãofoi efetuada a separação dos diferentes constituintes das plantas.

A decomposição foi avaliada em bolsas de poliéster com dimensões de 0,20 x 0,20 m emal ha de 0,5 mm. Cada bolsa, contendo os resíduos culturais, foi considerada como a unidade experimental. As bol sas 
foram distribuídas na superfície do solo das parcelas onde foram coletados os resíduos culturais, em delineamento experimental de blocos ao acaso, com quatro repeti ções. Os constituintes das plantas foram cortados manualmente em pedaços de aproximadamente $0,19 \mathrm{~m}$ antes de serem acondicionados nas bolsas.

A quantidade deMS de cada espécie, a ser colocada no interior das bolsas de decomposição, foi estimada a partir da MSA de cada tratamento. Uma amostra de cada tratamento, preparada da mesma maneira que aquel as col ocadas nas bol sas que foram distribuídas no campo, foi submetida à secagem em estufa a $65^{\circ} \mathrm{C}$ e posterior moagem em moinho Willey, para determinação das quantidades de $\mathrm{MS}, \mathrm{N}$ e $\mathrm{C}$ adicionadas inicialmentenas bolsas (Quadro 2). F oram utilizadas 28 bol sas para cada tratamento, eem cada data de aval iação eram col etadas quatro bolsas (uma por tratamento por bloco). As coletas foram real izadas aos sete, 14, 21, 28, 57, 117 e 164 dias após a colocação das bolsas no campo. A pós cada coleta, os resíduos culturais eram retirados do interior das bolsas e submetidos à secagem em estufa a $65^{\circ} \mathrm{C}$ até massa constante, para posterior pesagem edeterminação da MS remanescente.

A taxa de decomposi ção dos resíduos culturais das plantas de cobertura foi estimada ajustando-se um model o deregressãonãolinear aos val ores observados, conforme proposto por Wieder \& Lang (1982). O modelo ajustado tem a seguinte equação:

$$
M S R=A e^{-k a t}+(100-A) e^{-k b t}
$$

em que, $M S R=$ percentagem de matéria seca remanescente no tempo t (dias); e ka, kb=taxas constantes de decomposição da matéria seca do compartimento mais facilmente decomponível $(A)$ e

Quadro 2. Composição química e quantidades de matéria seca, carbono (C) e nitrogênio (N) adicionadas nas bolsas de decomposição em cada tratamento

\begin{tabular}{|c|c|c|c|c|c|c|}
\hline \multirow{2}{*}{ Tratamento ${ }^{(1)}$} & \multicolumn{3}{|c|}{ Composição } & \multicolumn{3}{|c|}{ Quantidade adicionada } \\
\hline & C & $\mathbf{N}$ & $\mathbf{C} / \mathbf{N}$ & MS & C & $\mathbf{N}$ \\
\hline & \multicolumn{2}{|c|}{$-\mathrm{g} \mathrm{kg}^{-1}$} & & \multicolumn{2}{|c|}{ _ Mgha-1_ } & $\mathrm{kg} \mathrm{ha}^{-1}$ \\
\hline C & 420,0 & 13,6 & 30,9 & 3,56 & 1,5 & 46,3 \\
\hline$A$ & 422,5 & 18,5 & 22,8 & 2,42 & 1,0 & 44,8 \\
\hline EF & 420,0 & 29,0 & 14,5 & 5,54 & 2,3 & 160,7 \\
\hline $\mathrm{N}$ & 395,0 & 23,9 & 16,5 & 8,71 & 3,4 & 208,2 \\
\hline$C+E F$ & 420,0 & 29,1 & 15,5 & 6,27 & 2,6 & 182,5 \\
\hline $\mathrm{C}+\mathrm{N}$ & 397,5 & 21,0 & 18,9 & 7,74 & 3,1 & 162,5 \\
\hline $\mathrm{C}+\mathrm{E}$ & 422,5 & 24,5 & 17,2 & 4,61 & 1,9 & 112,9 \\
\hline$A+N$ & 400,0 & 25,4 & 15,7 & 8,12 & 3,2 & 206,2 \\
\hline$A+E$ & 412,5 & 28,6 & 14,4 & 3,75 & 1,5 & 107,3 \\
\hline
\end{tabular}

do compartimento mais recalcitrante (100-A), respectivamente. Essemodelo considera quea MS dos resíduos culturais pode ser dividida em dois compartimentos ediminui exponencialmente a taxas constantes; a primeira fração étransformada a taxas mais el evadas do quea segunda, queé de mais difícil decomposição (recalcitrante).

A partir dos valores da taxa constante de decomposição da MS, cal cul ou-se o tempo de meiavida $\left(t_{1 / 2}\right)$, ou seja, o tempo necessário para que $50 \%$ da MS decada compartimento fosse decomposta. Para esse cálculo, utilizou-se a fórmula a seguir, cuja dedução éapresentada em Paul \& Clark (1996):

$$
t_{1 / 2}=0,693 / k_{(a, b)}
$$

A análise estatística, dos dados obtidos para a produção de MS, acúmulo de $\mathrm{N}$ e relação $\mathrm{C} / \mathrm{N}$, foi feita por meio da análise da variância, e as médias dos tratamentos foram comparadas pelo teste de Tukey a $5 \%$

\section{RESULTADOS E DISCUSSÃO}

\section{Produção de matéria seca}

O nabo forrageiro foi a espécie que, em cultura pura, produziu a maior quantidadedeMS $\left(8,3 \mathrm{Mg} \mathrm{ha}^{-1}\right)$, seguido da ervilha forrageira $\left(5,5 \mathrm{Mg} \mathrm{ha}^{-1}\right)$, do centeio (4,1 $\mathrm{Mg} \mathrm{ha}^{-1}$ ) e da aveia-preta (3,3 $\mathrm{Mg} \mathrm{ha}^{-1}$ ) (Quadro 3). Esse resultado difere do encontrado em outros trabalhos, como o de Giacomini et al. (2003), em queo nabo superou a produção de MS da aveia em apenas $20 \%$. No presentetrabalho, a produção deMS do nabo foi superior à da aveia em $150 \%$. O elevado teor de MOS do local do experimento (Quadro 1), o N mineralizado dos resíduos culturais da cultura anterior (soja), que segundo Wiethölter (1996) pode aumentar a disponibilidade de $\mathrm{N}$ em 17 a $59 \mathrm{~kg} \mathrm{ha}^{-1}$, ea provável maior eficiência do nabo em assimilar o $\mathrm{N}$ disponível do solo são fatores que podem explicar esse resultado.

Comparando a produção de MS entreas espécies, ainda em cultura pura, observa-se no quadro 3 quea produção de MS da ervilha forrageira foi superior à da aveia e do centeio em 67 e $34 \%$, respectivamente. As baixas temperaturas ea estiagem que ocorreram no início do desenvol vimento vegetativo das espécies provocaram atraso no desenvol vimento da aveia e do centeio, o que não foi observado na ervilha forrageira e no nabo. Além disso, quando a aveia foi coletada para avaliação de matéria seca, a espécie encontravaseno estádio deemborrachamento, nãotendoatingido ainda o potencial de produção deMS para as condições em que o experimento foi conduzido. Esse resultado corrobora aqueles obtidos por Crusciol et al. (2008), em que a col eta relativamente precoce da aveia, no final do perfilhamento, resultou na baixa produção de 
MS da cultura (2.953 kg ha-1). A col eta da aveia foi real izada antes doflorescimento pleno, a fim deevitar a semeadura do milhofora da época recomendada aos produtores da região.

Quanto ao cultivo consorciado das espécies, as maiores produções de MS foram encontradas nos tratamentos com nabo (Quadro 3). A aveia e o centeio consorciados com nabo produziram apenas 27,3 (0,9 $\left.\mathrm{Mg} \mathrm{ha}^{-1}\right)$ e $22,0 \%\left(0,9 \mathrm{Mg} \mathrm{ha}^{-1}\right)$ da matéria seca produzida por essas duas espécies em cultura pura, respectivamente. J á o nabo, quando consorciado com as duas poáceas, produziu em média $6,55 \mathrm{Mg} \mathrm{ha}^{-1}$, não diferindo significativamente da sua produção em cultura pura. A supremacia do nabo nos consórcios com aveia e centeio pode ser atribuída ao rápido crescimento inicial dessa espécie, em relação às poáceas. Avaliando o consórcio entre aveia e nabo, Giacomini et al. (2003) concluíram que em sol os com maior disponibilidade de $\mathrm{N}$ o nabo apresenta maior taxa de crescimento que a aveia, competindo mais eficientemente por nutrientes, água eradiação solar. Isso justifica os resultados obtidos com o nabo no presentetrabalho, embora a densidade de semeadura utilizada com as espécies consorciadas tenha sido aquela recomendada. Uma alternativa para esse problema de predominância do nabo sobre as poáceas em sol os com el evados teores de matéria orgânica e, portanto, com maior potencial defornecimento de $\mathrm{N}$ consiste na redução da proporção da crucífera nos consórcios. Trabal hos futuros são necessários para estabelecer a mel hor proporção de nabo em sol os com essas características.

Quando o centei o foi consorciado com ervilhaca, a produçãototal de MS do consórcio foi $17 \%$ superior à do centeio em cultura pura $\left(4,1 \mathrm{Mg} \mathrm{ha}^{-1}\right)$, embora essa diferença nãotenha sidosignificativa. Comportamento semel hantefoi observado para o consórcio entreaveiapreta e ervil haca e entre centeio e ervil ha forrageira. Esse resultado em que os consórcios apresentaram maior produção de MS do que as gramíneas em culturas puras ocorreu possivel mente devidoà baixa produção deMS obtida com as gramíneas. Em estudo realizado por Giacomini et al. (2003) durantetrês anos, a produção de MS pela aveia superou a da ervilhaca; a inclusão da aveia no consórcio com a leguminosa resultou em aumento na MS produzida em relaçãoà leguminosa em cultura pura. Dois aspectos interessantes podem ser destacados no consórcio entre centeio e ervilha forrageira. O primeiro é que a produção de matéria seca do consórcio aumentou 46 \% em relação ao centei o em cultura pura. O segundo refere-se ao fato dea produção da ervilha forrageira ter diminuído em apenas $21,8 \%$ em relação ao seu cultivo em cultura pura, enquanto a produção do centeio consorciado diminuiu de 4,1 para 1,7 $\mathrm{Mg} \mathrm{ha}^{-1}$ (59\%). Esseresultado, que deverá ser confirmadoem estudos futuros, indica que a ervilha forrageira apresenta el evada capaci dade de competi ção com as poáceas pel os recursos ambientais disponíveis.

A produçãomédia de MS das plantas decobertura foi de 5,6 $\mathrm{Mg} \mathrm{ha}^{-1}$, sendo de 5,3 $\mathrm{Mg} \mathrm{ha}^{-1}$ nas espécies em cultura pura e de $5,9 \mathrm{Mg} \mathrm{ha}^{-1}$ nas espécies consorciadas (Quadro 3). Esseresultado indica queo consórcio entre as plantas de cobertura é uma alternativa favorável em relação ao seu cultivo em cultura pura, já que foi possível aumentar a produção de MS em $11 \%$.

Outro aspecto a ser destacado refere-se à maior produção de MS das espécies de cobertura em relação à vegetação espontânea do tratamento em pousio. A MS dessetratamento al cançou apenas $13 \%$ daquela produzida pela média dos tratamentos com plantas decobertura. Esseresultado demonstra a importância da ind usão de plantas de cobertura no outono/inverno em sistemas deculturas, não somenteno que concerne à adição de $\mathrm{C}$ e $\mathrm{N}$ ao solo e ciclagem de nutrientes, mas também na proteção do sol o contra os processos erosivos.

\section{Acúmulo de nitrogênio na fitomassa}

Entre as espécies em cultura pura, o nabo ea ervilha forrageira acumularam as maiores quantidades de $\mathrm{N}$ na parte aérea, sem diferirem significativamenteentresi (Figura 1). A quantidade média de $\mathrm{N}$ acumulada por essas duas espécies foi de 190,3 $\mathrm{kg} \mathrm{ha}^{-1}$, superando a média das duas poáceas (aveia e centeio) em 136,9 kg ha-1 (256\%). A el evada quantidade de $\mathrm{N}$ acumulada pela ervilha forrageira, em relaçãoàs poáceas, deve-seao fato dea leguminosa fixar $\mathrm{N}_{2}$ atmosférico em simbiose com rizóbio. J á o elevadoacúmulo deN pelonabo, superando atémesmo a leguminosa em $29,1 \mathrm{~kg} \mathrm{ha}^{-1}(16,6 \%)$, nãoéverificado em todos os trabal hos, como, por exemplo, naquele realizado por Möller \& Reents (2009), em quea ervilha e a ervilhaca acumularam quantidades de $\mathrm{N}$ muito mai ores do que as do nabo. O resultado obtido neste trabal ho com o nabo deveestar relacionado aos teores relativamenteelevados de MOS do experimento, oque deve ter disponibilizado $\mathrm{N}$ à cultura. A elevada capacidade deextração de $\mathrm{N}$ mineral do solo, por essa crucífera, inclusive de camadas mais profundas, foi relatada por Silva et al. (2006).

A quantidade de $\mathrm{N}$ acumulada nos tratamentos com consórcio de espécies variou de $118 \mathrm{~kg} \mathrm{ha}^{-1}$ no consórcio entre aveia e ervilhaca a $184,6 \mathrm{~kg} \mathrm{ha}^{-1}$ no consórcio entre centeio e nabo, com valor médio de $153,3 \mathrm{~kg} \mathrm{ha}^{-1}$, considerando os cinco consórcios avaliados. Essa quantidade média de $\mathrm{N}$ acumulada pela fitomassa dos consórcios é 187 \% maior do quea quantidade média de $\mathrm{N}$ acumulada pelas poáceas. Apenas os consórcios entre centei o e ervilhaca e entre aveia e ervilhaca acumularam quantidades de $\mathrm{N}$ significativamentemenores do quea ervilha forrageira e o nabo em culturas puras (Figura 1 ).

Analisando o consórcio entreervilha forrageira e centeio, observa-se que o acúmulo de $\mathrm{N}$ não diferiu significativamente daquele da ervil ha forrageira em cultura pura. Além disso, a quantidade de $\mathrm{N}$ acumulada por esse consórcio foi próxima àquela 
acumulada nos tratamentos com o nabo consorciado à aveia e ao centeio e superior em 40,3\% ao consórcio entre aveia-preta e ervilhaca, que éo mais utilizado pelos agricultores no Rio Grande do Sul. Esses resultados evidenciam que o consórcio entrecenteio e ervilha forrageira - culturas ainda pouco utilizadas, principalmente nos Latossolos do Planalto do Rio Grande doSul - constitui uma alternativa promissora com vistas à combinação entre proteção ao solo no períodoinvernal (pela fitomassa) ena primavera verão (através dos resíduos culturais) efornecimento deN à cultura em sucessão em plantio direto.

Os consórcios entre centei o e nabo e entreaveia e nabo acumularam quantidades de $\mathrm{N}$ que não diferiram do nabo em cultura pura eforam, em média, 3,3 vezes superiores às do centeio e aveia em cultura pura, confirmandoa contribuição do nabo na ciclagem de $\mathrm{N}$ no solo, mesmo não sendo uma leguminosa. A vantagem do cultivo consorciado entrenabo e poáceas é que os resíduos culturais do consórcio são mais lentamentedecompostos nosol o do queaqueles do nabo em cultura pura, conforme será demonstrado na sequência destetrabal ho.

No presentetrabalho, a ervil haca nãofoi avaliada em cultura pura pel ofato deessa modalidade decultivo da espécieser muito pouco utilizada pel os produtores, já que os resíduos culturais são rapidamente decompostos após o manejo da espécie. Por isso, a leguminosa foi consorciada com o centeioe com a aveia. Observa-seque a quantidade acumulada de $\mathrm{N}$ nesses dois consórcios foi superior no centei o com ervilhaca em $16 \mathrm{~kg} \mathrm{ha}^{-1}$, embora sem diferenças significativas entre ambos (Figura 1). Comparativamente às quantidades deN acumuladas pel ocenteioe pela aveia em cultura pura, o aumento no acúmulo de $\mathrm{N}$ proporcionado pela ind usão da ervilhaca nos consórcios com essas duas poáceas foi de 80,8 (151,8 \%) e 64,3 $(119,7 \%) \mathrm{kg} \mathrm{ha}^{-1}$, respectivamente.

Analisando conjuntamente os resultados relativos à produção dematéria seca (Quadro 3) eo acúmulo de $\mathrm{N}$ nos diferentes tratamentos (Figura 1 ), percebe-se que a inclusão de leguminosas em consórcio com poáceas possibilita a obtenção de produção defitomassa equival ente ou até mesmo superior à das poáceas em cultura pura, com a vantagem de aumentar significativamente o aporte de $\mathrm{N}$ ao solo, via fixação biológica de N (FBN). O nabo, por sua vez, embora não apresente FBN, mostrou-se muito mais eficiente noaproveitamento do $\mathrm{N}$ do solo do queas duas poáceas avaliadas (centeio e aveia), acumulandotanto ou mais $\mathrm{N}$ do que as próprias leguminosas (ervilha forrageira e ervilhaca). Todavia, é preciso avaliar em estudos futuros, em L atossol os do Planal to do Rio Grande do Sul, a relação da produção de fitomassa e acúmul o de $\mathrm{N}$ do nabo com os teores de MOS e com a cultura antecessora. Caso sejam confirmados os resultados obti dos neste trabal ho, o nabo passa a constituir uma importante al ternativa de cultivo no outono/inverno visando à ciclagem de $\mathrm{N}$ no sistema e à proteção do solo contra a erosão, principalmente quando essa crucífera for consorciada com poáceas. Além disso, a maior facilidade na produção e o menor custo na aquisi ção de sementes poderão favorecer a escolha do nabo como planta de cobertura de solo no outono/ inverno.

Apesar dessas características importantes apresentados pel o nabo nestee em outros trabal hos (Giacomini et al., 2001; Crusciol et al., 2005; Strieder et al., 2006; Silva et al., 2007), é relevante destacar que ele não apresenta capacidade de associação simbiótica com bactérias fixadoras de $\mathrm{N}$ e, por isso,

Quadro 3. Produção de matéria da parte aérea seca das espécies de plantas de cobertura de solo no outono/ inverno em cultura pura e em consórcio.

\begin{tabular}{|c|c|c|c|c|c|c|c|}
\hline \multirow{2}{*}{ Tratamento $^{(1)}$} & \multicolumn{6}{|c|}{ Matéria seca } & \multirow[b]{2}{*}{ Total } \\
\hline & Centeio & Aveia & Ervilha & Nabo & Ervilhaca & Pousio & \\
\hline & & & - & & & & \\
\hline C & $4,1 a^{(2)}$ & - & - & - & - & - & $4,1 \mathrm{de}$ \\
\hline$A$ & - & $3,3 a$ & - & - & - & - & $3,3 \mathrm{e}$ \\
\hline EF & - & - & $5,5 a$ & - & - & - & $5,5 \mathrm{cde}$ \\
\hline $\mathrm{N}$ & - & - & - & $8,3 a$ & - & - & $8,3 a$ \\
\hline$C+E F$ & $1,7 \mathrm{bc}$ & - & $4,3 a$ & - & - & - & $6,0 \mathrm{bcd}$ \\
\hline $\mathrm{C}+\mathrm{N}$ & $0,9 c$ & - & - & $6,9 a$ & - & - & $7,8 a b$ \\
\hline$C+E$ & $2,3 \mathrm{~b}$ & - & - & - & $2,5 \mathrm{a}$ & - & $4,8 \mathrm{de}$ \\
\hline$A+N$ & - & $0,9 \mathrm{~b}$ & - & $6,2 \mathrm{a}$ & - & - & $7,1 \mathrm{abc}$ \\
\hline$A+E$ & - & $1,6 \mathrm{~b}$ & - & - & $2,2 \mathrm{a}$ & - & $3,8 \mathrm{de}$ \\
\hline Pousio ${ }^{(3)}$ & - & - & - & - & - & 0,7 & $0,7 \mathrm{f}$ \\
\hline
\end{tabular}

${ }^{(1)} \mathrm{C}=$ centeio; $\mathrm{A}=$ aveia-preta; $\mathrm{EF}=$ ervilha forrageira; $\mathrm{NF}=$ nabo forrageiro; $\mathrm{E}=$ ervilhaca comum. ${ }^{\left({ }^{2}\right)}$ Médias seguidas de mesma letra nas colunas não diferem entre si pelo teste de Tukey a $5 \%{ }^{(3)} \mathrm{A}$ MS do tratamento em pousio refere-se à vegetação espontânea da área. Média de quatro repetições. 


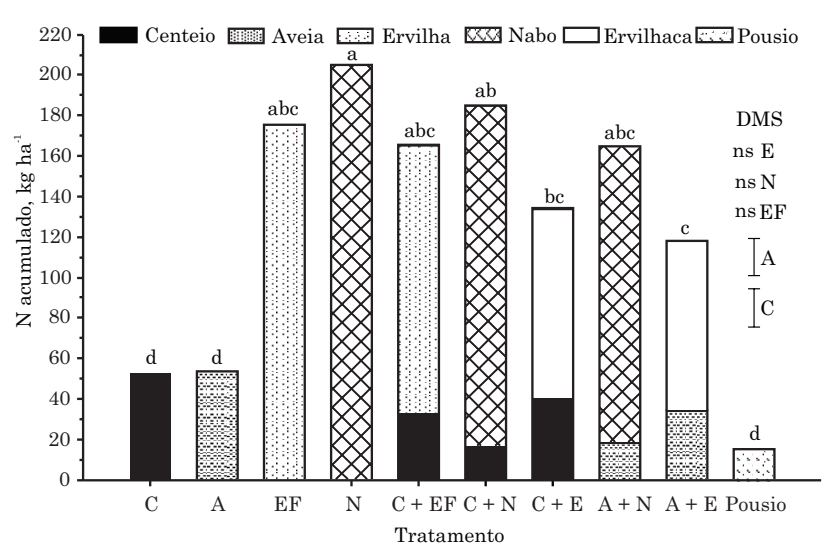

Figura 1. Acúmulo de nitrogênio (N) na parte aérea das plantas de cobertura, em cultura pura e em consórcio. Médias das quantidades totais de $\mathbf{N}$ seguidas de mesma letra não diferem entre si pelo teste de Tukey a $5 \%$. As barras verticais correspondem à di ferença míni ma significativa (Tukey $5 \%$ ) para a quantidade de $\mathrm{N}$ acumulada por cada espécie. ns=não significativo. $\mathrm{C}=$ centeio; $A=$ aveia-preta; $E F=$ ervil ha forragei $r a ; N F=$ nabo forrageiro; $\mathrm{E}=$ ervil haca comum.

não promove o aporte externo de $\mathrm{N}$ ao sistema, como o fazem as leguminosas por meio da FBN. Daí a importância de avaliar o impacto do cultivo continuado do nabo no inverno sobre o potencial de fornecimento de $\mathrm{N}$ pelo solo, já que ele depende do N disponibilizado por meio da mi neralização da MOS. De qualquer modo, a produção elevada de nabo alcançada no presente estudo o coloca como uma alternativa para uso nos Latossolos do Planal to do Rio Grande do Sul, visando à rotação no outono/ inverno com outras plantas de cobertura, como a ervilhaca ea ervilha forrageira.

Comparando o acúmulo de $\mathrm{N}$ entreas poáceas em cultura pura e a vegetação espontânea do pousio, verifica-se que a vegetação espontânea da área acumulou apenas $28 \%$ da quantidade média de $\mathrm{N}$ acumulada pel o centeio e pela aveia. E sse resultado confirma os encontrados por Heinrichs et al. (2001) e Giacomini et al. (2003), demonstrando que, além de adicionarem fitomassa e $\mathrm{C}$ ao solo, as poáceas podem contribuir para a diminuição das perdas de $\mathrm{N}$ por lixiviação de nitrato no perfil do solo, no período invernal, imobilizando-o no tecido vegetal .

\section{Relação C/N}

Os maiores valores para a relação $\mathrm{C} / \mathrm{N}$ das espécies em cultura pura foram encontrados no centeio (34/1) e na aveia (27/1), eos menores, na ervil ha forrageira (14/1) e no nabo forrageiro (17/1) (Quadro 4). Nos tratamentos em que o centeio foi consorciado com ervilha forragei ra e com nabo, a relação $\mathrm{C} / \mathrm{N}$ do tecido vegetal desses consórcios foi mais próxima à encontrada com o nabo e a ervilha forrageira em cultura pura do que daquela do centeio em cultura pura (Quadro 4). O mesmo foi verificado para o consórcio entre aveia-preta e ervilhaca comum, confirmando resultados encontrados por Heinrichs et al. (2001) eGiacomini (2001), em que as relações C/N da aveia em cultura pura foram de 33,9 e 36,5, respectivamente, enquanto a $\mathrm{C} / \mathrm{N}$ dos resíduos culturais do consórcio aveia +ervilhaca foi de 24 e 18,6 , respectivamente.

Deacordo com Giacomini et al . (2003), o consórcio entre diferentes espécies proporciona a produção de uma fitomassa cuja relação $C / N$ éintermediária àquela das espécies em cultura pura. Por meiodessa estratégia de cultivo das plantas de cobertura - ilustrada no presente trabalho pelos consórcios do centeio com ervilha forrageira enabo - busca-sealterar a taxa de decomposição de resíduos culturais de modo a proporcionar, simultaneamente, cobertura mais eficiente eduradoura do solo emel hor sincronia entre o fornecimento e a demanda de $\mathrm{N}$ pelas culturas em sucessão.

Os processos microbianos de imobilização e mineralização de $\mathrm{N}$ dependem, em grande parte, da relação C/N dos resíduos culturais. Partindo desse pressuposto, Allison (1966) afirmou que materiais com valores de $\mathrm{C} / \mathrm{N}$ entre 25 e 30 apresentam equilíbrio entre mineralização e imobilização. Assim, pode-se inferir que nos tratamentos com nabo e ervilha forragei ra em cultura pura e naqueles com consórcios entre espécies haja predominância da mineral ização, resultando em aumento na quantidade de $\mathrm{N}$ mineral do sol o durantea decomposição dos resíduos culturais. Por outro lado, a relação $\mathrm{C} / \mathrm{N}$ do centeio e da aveia sugere ocorrência deimobilização líquida deN durante a sua decomposi ção no solo.

Um resultado a destacar no presente trabalho refere-seà alteração da relação $\mathrm{C} / \mathrm{N}$ do centeio, quando consorciado ao nabo, à ervilha forrageira eà ervilhaca, e da aveia, quando consorciada ao nabo eà ervilhaca. Os resultados do quadro 4 mostram que a relação C/ $\mathrm{N}$ do centeio em cultura pura foi reduzida em $35,3 \%$, quando comparada com a $\mathrm{C} / \mathrm{N}$ da espécieconsorciada à ervilha forrageira. $A$ redução média da $C / N$ do centeio, quando consorciado ao nabo eà ervilhaca, foi de $27,9 \%$. Comportamento semel hante foi observado na aveia, em que a sua relação $\mathrm{C} / \mathrm{N}$ diminuiu de $27 / 1$ para 20/1 (26\%), na média dos consórcios da espécie com o nabo e a ervilhaca. Resultados semel hantes foram relatados por Giacomini et al. (2003) e podem ser atribuídos a diversos fatores. A redução na população de plantas das poáceas, quando consorciadas, diminui a competição entre plantas pelo $\mathrm{N}$ disponível do solo, aumentando a concentração de $\mathrm{N}$ no tecido vegetal. Além disso, no caso das leguminosas, a senescência precocedenódulos, a queda edecomposição das fol has mais vel has ea exđreção de exsudatos radiculares ricos em $\mathrm{N}$ podem contribuir para o fornecimento de $\mathrm{N}$ às poáceas nos consórcios, como destacado por Ta \& Faris (1987). 
Quadro 4. Relação carbono/nitrogênio da parte aérea das espécies de plantas de cobertura de solo no outono/ inverno em cultura pura e em consórcio

\begin{tabular}{|c|c|c|c|c|c|c|c|}
\hline \multirow{2}{*}{ Tratamento $^{(1)}$} & \multicolumn{6}{|c|}{ Relação carbono/nitrogênio } & \multirow[b]{2}{*}{ Total } \\
\hline & Centeio & Aveia & Ervilha & Nabo & Ervilhaca & Pousio & \\
\hline & & & - & 1 & & & \\
\hline C & $34 a^{(2)}$ & - & - & - & - & - & $34 \mathrm{a}$ \\
\hline A & - & $27 a$ & - & - & - & - & $27 \mathrm{~b}$ \\
\hline EF & - & - & $14 \mathrm{a}$ & - & - & - & $14 \mathrm{e}$ \\
\hline $\mathrm{N}$ & - & - & - & $17 a$ & - & - & $17 \mathrm{de}$ \\
\hline$C+E^{(4)}$ & $22 \mathrm{~b}$ & - & $15 \mathrm{a}$ & - & - & - & $17 \mathrm{de}$ \\
\hline $\mathrm{C}+\mathrm{N}$ & $24 \mathrm{~b}$ & - & - & 17 a & - & - & $18 \mathrm{~cd}$ \\
\hline$C+E$ & $25 \mathrm{~b}$ & - & - & - & $12 \mathrm{a}$ & - & 18 cde \\
\hline$A+N$ & - & $20 \mathrm{~b}$ & - & $18 a$ & - & - & $18 \mathrm{~cd}$ \\
\hline$A+E$ & - & $20 \mathrm{~b}$ & - & - & $12 \mathrm{a}$ & - & $15 \mathrm{de}$ \\
\hline Pousio(3) & - & - & - & - & - & - & $22 c$ \\
\hline
\end{tabular}

${ }^{(1)} \mathrm{C}=$ centeio; $\mathrm{A}=$ aveia-preta; $\mathrm{EF}=$ =rvilha forrageira; $\mathrm{NF}=$ nabo forrageiro; $\mathrm{E}=$ =ervilhaca comum. ${ }^{(2)} \mathrm{Médias}$ seguidas de mesma letra na coluna não diferem entre si pelo teste de Tukey $5 \%$. ${ }^{(3)} \mathrm{A}$ relação $\mathrm{C} / \mathrm{N}$ do tratamento em pousio refere-se à vegetação espontânea da área. ${ }^{(4)} \mathrm{A}$ relação $\mathrm{C} / \mathrm{N}$ dos consórcios foi determinada por meio de média ponderada entre os valores de matéria seca obtidos para cada espécie do consórcio e os respectivos valores de C/N. Média de quatro repetições.

\section{Decomposição dos resíduos culturais}

De maneira geral, a cinética de decomposição dos resíduos culturais das plantas de cobertura, avaliada por meio das quantidades remanescentes de matéria seca ao longo do tempo, foi similar tanto nas espécies em cultura pura (Figura 2a) quanto em consórcio (Figura 2b). Nos dois casos, observa-se uma fase inicial, com rápida redução nas quantidades remanescentes dematéria seca, seguida de outra mais lenta, o que coincidecom resultados obtidos em outros trabalhos (Giacomini et al., 2003; Crusciol et al., 2005; Marcolini, 2009).

Considerando os primeiros 21 dias, quefoi operíodo de maior decomposição, observa-se quea quantidade remanescente de matéria seca no interior das sacolas de decomposição era de aproximadamente $57 \%$ na ervilha forrageira, $58 \%$ no nabo forragei ro, $59 \%$ na aveia-preta e $72 \%$ no centeio (Figura 2a). Contrariamente ao observado em outros trabal hos, como o realizado por Aita \& Giacomini (2003), a aveiapreta apresentou quantidade de matéria seca do compartimento lábil relativamente próxima à da ervilha forrageira e do nabo, bem como um tempo de meia-vida dessecompartimento próximoaoverificado nonabo (Quadro5). Era deseesperar menor proporção da matéria seca lábil e menor taxa constante de decomposição nos resíduos culturais da aveia. É provável que esses resultados devam-se ao fato dea aveia ter apresentado relação $\mathrm{C} / \mathrm{N}$ relativamentebaixa $(22,8 / 1)$ dos resíduos culturais (Quadro 2). Essa baixa relação $\mathrm{C} / \mathrm{N}$ da aveia pode ser atribuída ao fato dea cultura estar em estádiofinal de perfilhamento einício deemborrachamento quando col etada para a confecção das sacolas de decomposição, além do provável el evado potencial de fornecimento de $\mathrm{N}$ pelo solo da área experimental. Convém destacar que, na maioria dos trabalhos, a coleta da aveia para avaliar sua decomposição ocorre quando a planta encontra-se no estádio de florescimento pleno. Neste trabalho, as espécies foram coletadas e manejadas no mesmo dia, e o estádio de desenvol vimento das espécies em que isso ocorreu foi estabelecido em função do desenvol vimento das espécies mais precoces (nabo e ervilha).

Entre as espécies em cultura pura (Quadro 5), o centeio foi a que apresentou a menor proporção de matéria seca no compartimento lábil (39,4\%). Pelo fato de também ser uma poácea, esperava-se que a aveia apresentasse comportamento similar ao observado pel o centeio. Todavia, observa-se na figura $2 a$ eno quadro 5 quea decomposição das duas culturas ocorreu de forma distinta: na aveia, a proporção da matéria seca mais recalcitrante (100-A) foi de aproximadamente $45 \%$ com tempo de meia-vida de 433 dias, enquanto no centeio a matéria seca de mais difícil decomposição representou cerca de $60 \%$, com tempo de meia-vida de 277 dias. É provável queesse comportamento distinto entre as duas poáceas esteja ligado às diferenças na sua relação C/N (Quadro 2), como também a diferenças na sua constituiçãofísica (proporção entretalos efol has) e, principalmente, na composi ção bi oquímica do tecido vegetal.

A ervilha forrageira foi a espécie em cultura pura que apresentou a maior taxa constante de decomposição $\left(0,0752 \mathrm{dia}^{-1}\right)$ do compartimento mais facilmentedecomponível (A), oqual representou 46,9\% da matéria seca adicionada ao sol o pela leguminosa (Quadro5). É provável queesse compartimento seja 


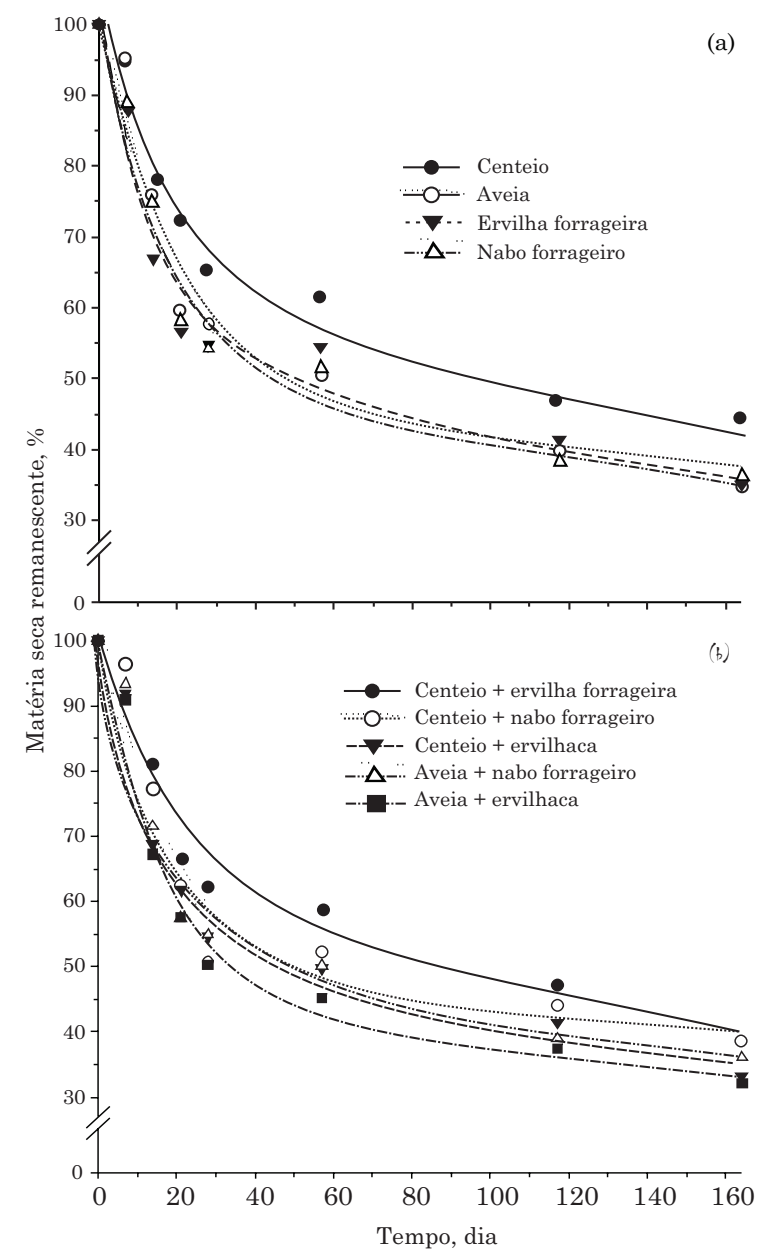

Figura 2. Matéria seca remanescente dos resíduos culturais deplantas decobertura em cultura pura (a) e em consórcio (b), em avaliações realizadas em campo até 164 dias após a distribuição das sacolas de decomposição na superfície do solo. constituído sobretudo pelas fol has da ervilha, as quais representam uma fonte de $\mathrm{C}$ e de energia utilizada inicialmente pela população microbiana do solo.

Comparandoos parâmetros do model o encontrados para tratamentos com centei o enabo em cultura pura ao tratamentoem que o centeiofoi consorciado ao nabo, observa-se que a inclusão do nabo aumentou a proporção de matéria seca lábil, em relação ao centeio puro. O mesmo não ocorreu para o consórcio entre aveia enabo, uma vez que os parâmetros encontrados para as duas culturas sol tei ras foram rel ativamente próximos entre si (Quadro 5). Fazendo essa mesma comparaçãoentreos tratamentos com centeio eervilha forrageira em cultura pura eem consórcio, percebe-se que com a inclusão da ervilha não houve mudanças nos parâmetros do modelo, em relação ao centeio puro. Esperava-se quenotratamento em consórcio os val ores dos parâmetros fossem intermediários aos observados nas culturas sol teiras. Com base nas determinações realizadas, não é possível apontar as causas determinantes desseresultado.

\section{CONCLUSÕES}

1. O consórcio entre leguminosas e crucífera com gramíneas resul tou em mai or produção defitomassa e menor velocidadededecomposição dos resíduos culturais em relação ao cultivo destas em culturas puras.

2. O acúmulo de $\mathrm{N}$ pelos consórcios foi similar ao da ervilha forrageira enaboem cultura pura esuperior ao da aveia e centeio.

3. Quando consorciadas, a relação $\mathrm{C} / \mathrm{N}$ da fitomassa das plantas de cobertura foi intermediária àquela observada em cultura pura.

Quadro 5. Parâmetros dos modelos ajustados aos valores medidos de matéria seca remanescente, tempo de meia-vida $\left(t_{1 / 2}\right)$ da matéria seca de cada compartimento ae valores do coeficiente de determinação $\left(R^{2}\right)$ em cada tratamento

\begin{tabular}{|c|c|c|c|c|c|c|}
\hline \multirow{2}{*}{ Tratamento $^{(1)}$} & \multirow{2}{*}{$\mathbf{A}$} & \multirow{2}{*}{$\mathbf{k}_{\mathrm{a}}$} & \multirow{2}{*}{$\mathbf{k}_{\mathrm{b}}$} & \multicolumn{2}{|c|}{$t_{1 / 2}$} & \multirow{2}{*}{$\mathbf{R}^{2}$} \\
\hline & & & & A & $(100-\mathrm{A})$ & \\
\hline & $\%$ & 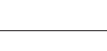 & - & 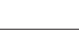 & - & \\
\hline \multicolumn{7}{|c|}{ Matéria seca remanescente $(\mathrm{MSR})^{(2)}$} \\
\hline C & 39,4 & 0,0567 & 0,0025 & 12,2 & 277 & 0,95 \\
\hline$A$ & 55,3 & 0,0527 & 0,0016 & 13,1 & 433 & 0,95 \\
\hline EF & 46,9 & 0,0752 & 0,0028 & 9,2 & 247 & 0,97 \\
\hline $\mathrm{N}$ & 52,9 & 0,0598 & 0,0021 & 11,6 & 330 & 0,97 \\
\hline$C+E F$ & 40,6 & 0,0575 & 0,0029 & 12,1 & 239 & 0,94 \\
\hline $\mathrm{C}+\mathrm{N}$ & 57,2 & 0,0525 & 0,0011 & 13,2 & 630 & 0,94 \\
\hline$C+E$ & 50,0 & 0,0649 & 0,0025 & 10,7 & 277 & 0,97 \\
\hline$A+N$ & 54,8 & 0,0586 & 0,0018 & 11,8 & 385 & 0,96 \\
\hline$A+E$ & 58,5 & 0,0595 & 0,0018 & 11,6 & 385 & 0,97 \\
\hline
\end{tabular}

${ }^{(1)} \mathrm{C}=$ centeio; $\mathrm{A}$ =aveia-preta; $\mathrm{EF}=$ =rvilha forrageira; $\mathrm{NF}$ =nabo forrageiro; $\mathrm{E}=$ =ervilhaca comum.

(2) $M S R=A e^{-k a t}+(100-A) e^{-k b t}$. 


\section{LITE RATURA CITADA}

AITA, C. \& GIACOMINI, S.J. Decomposição e liberação de nitrogênio de resíduos culturais de plantas de cobertura de solo solteiras e consorciadas. R. Bras. Ci. Solo, 27:601612, 2003.

AITA, C. \& GIACOMINI, S.J. Plantas de cobertura de solo em sistemas agrícolas. In: ALVES, B.J .R.; URQUIAGA, S.; AITA, C.; BODDEY, R.M.; J ANTALIA, C.P. \& CAMARGO, F.A.O., eds. Manejo de sistemas agrícolas: impacto no sequestro de $\mathrm{C}$ e nas emissões de gases de efeito estufa. Porto Alegre, Genesis, 2006. p.59-79.

ALLISON, F.E. The fate of nitrogen applied to soils. Adv. Agron., 18:219-258, 1966.

BASSO, C.J . É pocas de aplicação de nitrogênio para o milho cultivado em sucessão a plantas de cobertura de solo, no sistema plantio direto. Santa Maria, Universidade Federal de Santa Maria, 1999. 91p. (Tese de Mestrado)

BRASIL. Ministério da Agricultura. Departamento Nacional de Pesquisa Agropecuária. Divisão de Pesquisas Pedológicas. Levantamento de Reconhecimento dos Solos do Estado do Rio Grande do Sul. Recife, 1973. 431p. (Boletim Técnico, 30)

CRUSCIOL, C.A.C.; COTTICA, R.L.; LIMA, E.V.; ANDREOTTI, M.; MORO, E. \& MARCON, E. Persistência de palhada e liberação de nutrientes do nabo forrageiro no plantio direto. Pesq. Agropec. Bras., 40:161-168, 2005.

CRUSCIOL, C.A.C.; MORO, E.; LIMA, E.V. \& ANDREOTTI, M. Taxas de decomposição e de liberação de macronutrientes da palhada de aveia-preta em plantio direto. Bragantia, 67:481-489, 2008.

EMPRESA BRASILEIRA DE PESQUISA AGROPECUÁRIA EMBRAPA. Centro nacional de Pesquisa de Solos. Sistema brasileiro de classificação de solos. 2.ed. Brasília, Embrapa Produção de Informação, 2006. 306p.

GIACOMINI, S.J. Consorciação de plantas de cobertura no outono/inverno e fornecimento de nitrogênio ao milho em sistema plantio direto. Santa Maria, Universidade Federal de Santa Maria, 2001. 124p. (Tese de Mestrado)

GIACOMINI, S.J .; AITA, C.; VENDRUSCOLO, E.R.O.; CUBILLA, M.; NICOLOSO, R.S. \& FRIES, M.R. Matéria seca, relação $\mathrm{C} / \mathrm{N}$ e acúmulo de nitrogênio, fósforo e potássio em misturas de plantas de cobertura de solo. R. Bras. Ci. Solo, 27:325-334, 2003.

HEINRICHS, R.; AITA, C.; AMADO, T.J .C. \& FANCELLI, A.L. Cultivo consorciado de aveia e ervilhaca: Relação $\mathrm{C} / \mathrm{N}$ da fitomassa e produtividade do milho em sucessão. R. Bras. Ci. Solo, 25:331-340, 2001.
KLIEMANN, H.J .; BRAZ, A.J .P.B. \& SILVEIRA, P.M. Taxas de decomposição de resíduos de espécies de cobertura em Latossolo Vermelho distroférrico. Pesq. Agropec. Trop., 36:21-28, 2006.

KRAMBERGER, B.; GSELMAN, A.; J ANZEKOVIC, M.; KALIGARIC, M. \& BRACKO, B. Effects of cover crops on soil mineral nitrogen and on the yield and nitrogen content of maize. Eur. J . Agron., 31:103-109, 2009.

MARCELO, A.V.; CORÁ, J .E.; FERNANDES, C.; MARTINS, M.R. \& J ORGE, R.F. Crop sequences in no-tillage system: Effects on soil fertility and soybean, maize and rice yield. R. Bras. Ci. Solo, 33:417-428, 2009.

MARCOLINI, L.W. Produção e decomposição de coberturas vegetais de inverno e sua influência na infestação e fitossociologia de plantas daninhas. Piracicaba, Universidade de São Paulo, 2009. 77p. (Tese de Mestrado)

MÖLLER, K.\& REENTS, H. Effects of various cover crops after peas on nitrate leaching and nitrogen supply to succeeding winter wheat or potato crops. J. Plant Nutr. Soil Sci., 172:277-287, 2009.

PAUL, E.A. \& CLARK, F.E. Soil microbiology and biochemistry. 2.ed. New York, Academic Press, 1996. 340p.

SILVA, P.R.F.; ARGENTA, G.; SANGOI , L.; STRIEDER, M.L. \& SILVA, A.A. Estratégias de manejo de coberturas de solo no inverno para cultivo do milho em sucessão no sistema semeadura direta. Ci. Rural, 36:1011-1020, 2006.

SILVA, A.A.; SILVA, P.R.; SUHRE, E.; ARGENTA, G.; STRIEDER, M.L. \& RAMBO, L. Sistemas de coberturas de solo no inverno e seus efeitos sobre o rendimento de grãos do milho em sucessão. Ci. Rural, 37:928-935, 2007.

STRIEDER, M.L.; SILVA, P.R.F.; ANGHINONI, I.; MEURER, E.J .; RAMBO, L. \& ENDRIGO, P.C. É poca de aplicação da primeira dose de nitrogênio em cobertura em milho e espécies antecessoras de cobertura de inverno. R. Bras. Ci. Solo, 30:879-890, 2006.

TA, T.C. \& FARIS, M.A. Species variation in the fixation and transfer of $\mathrm{N}$ from legumes to associated grasses. Plant Soil, 98:265-274, 1987.

TORRES, J .L.R.; PEREIRA, M.G. \& FABIAN, A.J . Produção de fitomassa por plantas de cobertura e mineralização de seus resíduos em plantio direto. Pesq. Agropec. Bras., 43:421-428, 2008.

WIEDER, R.K. \& LANG, G.E. A critique of the analytical methods used in examining decomposition data obtained from litter bags. Ecology, 63:1636-1642, 1982.

WIETHÖLTER, S. Adubação nitrogenada no sistema plantio direto. Passo Fundo, Embrapa/CNPT, 1996. 44p. 